\title{
Red Cell Distribution Width and
}

\section{Inappropriateness of Left Ventricular Mass in Patients with Untreated Essential Hypertension}

\author{
Lizhang Chen ${ }^{1 \neq}$, Zhanzhan $\mathrm{Li}^{1}$, Yanyan $\mathrm{Li}^{2}$, Jing Xue ${ }^{1}$, Peng Chen ${ }^{3}$, Shipeng Yan ${ }^{1}$, \\ Caixiao Jiang ${ }^{1}$, Yingyun $\mathrm{Hu}^{4}$, Xing $\mathrm{QiaO}^{5 *}$ \\ 1 Department of Epidemiology and Health Statistics, School of Public Health, Central South University, \\ Changsha, Hunan Province, China, 2 Department of emergency, Henan Provincial Hospital of Traditional \\ Chinese Medicine, Zhengzhou, Henan Province, China, 3 Xiangya Medical School, Central South \\ University, Changsha, Hunan Province, China, 4 Hunan provincial tumor hospital, Changsha, Hunan \\ Province, China, 5 Department of Plastic Surgery, First Teaching Hospital of Xinjiang Medical University, \\ Urumqi, Xinjiang Uygur Autonomous Region, China
}

$\ddagger \mathrm{LC}$ is first author on this work.

*xingqiaoxj@126.com

\section{G open access}

Citation: Chen L, Li Z, Li Y, Xue J, Chen P, Yan S, et al. (2015) Red Cell Distribution Width and Inappropriateness of Left Ventricular Mass in Patients with Untreated Essential Hypertension. PLoS ONE 10(3): e0120300. doi:10.1371/journal.pone.0120300

Academic Editor: German E. Gonzalez, University of Buenos Aires, Faculty of Medicine, Cardiovascular Pathophysiology Institute, ARGENTINA

Received: April 3, 2014

Accepted: February 6, 2015

Published: March 20, 2015

Copyright: @ 2015 Chen et al. This is an open access article distributed under the terms of the Creative Commons Attribution License, which permits unrestricted use, distribution, and reproduction in any medium, provided the original author and source are credited.

Data Availability Statement: All relevant data are within the paper and its Supporting Information file.

Funding: This work was supported by Graduate Innovation Project of Hunan Province (CX2014B097), the fundamental research funds for the central universities of central south university (2014zzts069), and the Hunan Province Science and Technology Project (2014SK2013). The funders had no role in study design, data collection and analysis, decision to publish, or preparation of the manuscript.

\section{Abstract}

\section{Background}

Left ventricular hypertrophy ( $\mathrm{LVH})$ was suggested to be an important risk factor for hypertensive vascular complications. Previous studies had also shown that red cell distribution width (RDW) was associated with morbidity and mortality of cardiovascular disease. However, few have yet investigated possible association between RDW and LVH. The aim of the present study was to evaluate the relationship between LVH and RDW levels in hypertensive patients.

\section{Methods}

Physical examination, laboratory tests and echocardiography were conducted in 330 untreated newly diagnosed hypertensive patients attending the cardiology consultation unit at the Anzhen Hospital of Beijing. The multivariate logistic regression model was used to verify the independent association between RDW and LVH.

\section{Results}

174 patients without $\mathrm{LVH}$ and 156 patients with $\mathrm{LVH}$ were rolled in the study. The patients with LVH had higher mean SBP, albumin to creatinine ratio, total cholesterol, RDW and fasting glucose compared with non-LVH group. The mean HDL-cholesterol level was significantly lower in patients with $\mathrm{LVH}$ than patients without $\mathrm{LVH}$. The multiple logistic regression model suggested that patients with a higher RDW level were more likely to be LVH (OR=2.187, 95\% Cl: 1.447-3.307, $P<0.001$ ). Other predictive factors for $\mathrm{LVH}$ were mean 
Competing Interests: The authors have declared that no competing interests exist.
SBP, serum creatinine, glucose level. The receiver operating characteristics (ROC) curves indicated area under the curve was $0.688(95 \% \mathrm{Cl}: 0.635-0.737, \mathrm{P}<0.001)$ with a cut-off value of 12.9 , the RDW predicted LVH status among hypertensive patients with a sensitivity of $72.4 \%$ and a specificity of $60.3 \%$.

\section{Conclusions}

The higher RDW level was observed in the LVH group compared with the non-LVH group. RDW might be associated with LVH in hypertensive patients. These data highlight the role of RDW as a predictor of organ damage in essential hypertensive patients.

\section{Introduction}

According to 2013 European Society of Hypertension/Cardiology guidelines, the presence of subclinical organ damage is a fundamental and important factor in determining the estimated cardiovascular risk with proposed scale [1]. Left ventricular hypertrophy (LVH) is one of common subclinical organ damage induced by hypertension, and the presence of LVH increases mortality of cardiovascular disease [2-4]. According to some statistics, 20-40\% of hypertensive patients have the complication of LVH [5]. Identifying specific risk factor index for hypertensive patients has therefore great potential for preventing adverse cardiovascular events.

As an index of the routine blood cell count, red cell distribution width (RDW) is not only used to evaluate different types of anemia but also is a potent predictor of morbidity and mortality in a variety of settings, especially in many cardiovascular diseases. Several lines of evidences had suggested increased RDW was associated with a higher possibility of varieties of diseases. It is observed that increased RDW level appears to be an independent predictor of coronary heart disease risk in the general population [6]. Sánchez-Chaparro et al. conducted a cross-sectional study with 217,567 Spanish working people undergoing a routine physical checkup, and found that higher RDW level was associated with metabolic syndrome (MetS), a well-known multiple risk factors for cardiovascular disease [7]. The recent study also demonstrated that RDW is a useful marker in predicting inadequate reduction in nighttime BP in essential hypertension, and RDW values are closely related with inflammation status in hypertensive patients [8]. Hypertension is an inflammatory disorder. Previous studies have indicated a significant association between hypertension and inflammatory process $[9,10]$. The correlation between RDW and hypertension has been explored in a number of studies $[11,12]$.

Inflammatory status is significantly related to ineffective erythropoiesis, and it has been suggested that inflammatory cytokines such as interleukin (IL)-1 $\beta$, IL-6, tumor necrosis factor (TNF)- $\alpha$, desensitize bone marrow elytroid progenitors to erythropoiesis, inhibit red blood cell maturation and thereby promote anysocytosis $[13,14]$. Considering the above situation, we suppose that high blood pressure does damage to endotheliocyte promoting the secretin of inflammatory cytokines, and some inflammatory cytokines such as vascular endothelial growth factor (VEGF) play an important role in inducing myocardial hypertrophy [15]. Therefore, as a sensitive index of inflammatory status in this process, RDW could be a potential predictor of LVH in essential hypertensive patients. Various hematological and inflammatory biomarkers, such as mean platelet volume (MPV) [16], IL-10, IL-6 [17] have been used in clinical practice to evaluate related target organ damage in hypertensive patients. However, few have yet investigated possible association between RDW and LVH. The aim of the present study was to evaluate the relationship between LVH and RDW levels in hypertensive patients. 


\section{Materials and Methods}

\section{Study population}

In a cross-sectional study, data from 330 patients visiting the Cardiology Center at Anzhen Hospital of Beijing from November 2012 to October 2013 were analyzed. Hypertension was defined as systolic BP (SBP) $\geq 140 \mathrm{mmHg}$ or a diastolic BP (DBP) $\geqq 90 \mathrm{mmHg}$ and not treated with anti-hypertensive drug [18]. Among 513 patients who underwent physical examination, laboratory tests and echocardiography for evaluation of cardiac function, 330 patients' data (S1 Dataset) were collected by applying an exclusion criterion. According to echocardiographic examination, 156 patients with left ventricular hypertrophy (LVH) and 174 patients without LVH were enrolled in the present study. The patients' clinical and demographic characteristics including age, sex, and smoking habits were obtained through a standardized questionnaire. This study protocol was approved by the institutional review board of Xiangya Medical School, and written informed consent was obtained from all participants.

Exclusion criteria were as follows: patients who ever received treatment for hypertension; patients with secondary hypertension, heart failure, diabetes mellitus, renal or hepatic dysfunction, clinical evidence of cancer, systemic inflammatory disease, hematological system disorder and known coronary artery or cerebrovascular disease; disabling diseases such as dementia; and inability to cooperate.

\section{Laboratory examination}

Hematologic testing was performed on the ADVIA 120 (Bayer Diagnostics, Newbury, Berkshire, UK) automated hematology analyzer, which measures hemoglobin photometrically, including white blood cell counts, platelet counts, hemoglobin, mean corpuscular volume and RDW, optical laser light scattering for cell enumeration, flow cytometer and laser diffraction for red blood cell (RBC) counts. Serum creatinine (Scr) was measured on a Roche/Hitachi Modular System P (Roche Diagnostics GmbH, Mannheim, Germany) by creatinine Jaffe', rate blanked and compensated assay. Microalbuminuria was defined as that urine albumincreatinine ratio (ACR) is between $30 \mu \mathrm{g} / \mathrm{mg}$ and $300 \mu \mathrm{g} / \mathrm{mg}$ [19]. Urine albumin concentration was measured by immunoturbidimetric method [20]. In addition, fasting blood glucose level, creatinine level and fasting serum lipid status including total cholesterol, low-density lipoprotein (LDL), high-density lipoprotein (HDL), triglyceride, and high-sensitive C-reactive protein levels were also recorded. Body mass index (BMI) was calculated as weight $(\mathrm{kg})$ divided by height squared $\left(\mathrm{m}^{2}\right)$.

\section{Echocardiography}

All echocardiographic studies were performed on each subject by a single sonographer with a commercially available machine (Achieva, Philips Medical Systems) using a 1-5 MHz transducer. The overall single dimensional left ventricular measurements and the 2-dimension views were obtained according to the standard recommended by American Society of Echocardiography $[21,22]$. To reduce bias, the cardiologist was blinded to the results of urinalysis. Left ventricular mass was calculated by the following formula, LVM [23] $=1.04^{*} 0.8^{*}\left\{\left(\mathrm{VST}_{\mathrm{d}}{ }^{*}\right.\right.$ $\left.\left.\mathrm{LVID}_{\mathrm{d}}{ }^{*} \mathrm{PWT}_{\mathrm{d}}\right)^{3}-\left(\mathrm{LVID}_{\mathrm{d}}\right)^{3}\right\}+0.6$, where $\mathrm{IVS}_{\mathrm{d}}$ is diastolic interventricular septum, $\mathrm{LVD}_{\mathrm{d}}$ is diastolic left ventricular dimension, and $\mathrm{PWT}_{\mathrm{d}}$ is diastolic posterior wall thickness. LVMI $=$ LVM/BSA (Body Surface Area, BSA). LVH was defined as following: LVMI $\geq 125$ $\mathrm{g} / \mathrm{m}^{2}$ in men and $\geq 110 \mathrm{~g} / \mathrm{m}^{2}$ in women [24]. 


\section{Statistical analysis}

Data were reported as mean \pm standard deviation for quantitative variables and as percentages for qualitative variables. RDW was examined as a continuous variable. Differences between quantitative variables were tested by Student $t$ test. Differences between qualitative variables were tested using Chi-squared test. Pearson's correlation coefficients were calculated if appropriate. Multiple logistic regression analysis was used to calculate the odds ratio of independent variables. The receiver operating characteristics (ROC) curves explored the relationship between RDW and LVH. Statistical analysis was performed using SPSS version 17.0 (SPSS Inc, USA), GraphPad Prism 5 and MedCalc (http://www.medcalc.org/), and the level of statistical significance was defined as $P<0.05$.

\section{Results}

\section{General characteristics of the subjects}

As shown in Table 1, 174 patients without LVH and 156 patients with LVH were enrolled in the study. Among the 330 hypertensive patients, 19 were diabetes mellitus. In the comparisons of demographic, clinical, and echocardiographic characteristic between hypertensive patients with $\mathrm{LVH}$ and without $\mathrm{LVH}$, the average age was $46.8 \pm 7.9$ years and $46.3 \pm 7.7$ years respectively. The sex ratio (female/male) in the LVH group is 0.54 and 0.79 in the non-LVH. The patients with LVH had higher mean SBP $(138.8 \pm 12.3$ vs133.4 $\pm 9.3, P<0.001)$, albumin to creatinine ratio (47.9 \pm 56.4 vs $32.1 \pm 39.2, P=0.003)$, total cholesterol ( $5.4 \pm 0.8$ vs $5.2 \pm 0.9, P=0.011$ ), RDW (13.3 \pm 0.6 vs $12.8 \pm 0.8, P<0.001$, Fig. 1 ) and fasting glucose (5.8 \pm 0.6 vs $5.6 \pm 0.6$, $P=0.021)$ compared with non-LVH group. The mean HDL-cholesterol level was significantly lower in patients with $\mathrm{LVH}$ than patients without $\mathrm{LVH}(1.1 \pm 0.2$ vs $1.2 \pm 0.2, P<0.001)$.

The results of echocardiographic examination shown that patients with LVH had significantly longer interventricular septal thickness (IVST: $10.5 \pm 1.2$ vs $9.0 \pm 1.0, P<0.001$ ), left ventricular end-diastolic diameter (LVEDd: $49.5 \pm 4.0$ vs $45.4 \pm 4.5, P<0.001$ ), left ventricular end-systolic diameter (LVESd: $31.1 \pm 3.5$ vs $28.5 \pm 4.0, P<0.001$ ), posterior wall thickness (PWT: $10.3 \pm 1.3$ vs $9.0 \pm 1.9, P<0.001)$. The LVH group had significantly lower ejection fraction than the non-LVH group (EF, $64.7 \pm 7.1$ vs $66.8 \pm 5.3, P=0.002$ ). The mean left ventricular mass for two groups was $236.7 \pm 43.9$ and $169.3 \pm 30.5(P<0.001)$. Among these echocardiographic indexes, LVM, LVMI, $\mathrm{EF}$, and PWT were correlated with RDW in hypertensive patients. $\operatorname{LVM}(\mathrm{r}=0.24, P<0.001)$, LVMI $(r=0.26, P<0.001)$, and IVST $(r=0.191, P<0.001)$ have a positive relationship with RDW while EF $(\mathrm{r}=-0.13, P=0.016)$ suggested an inverse relationship with RDW (Table 2$)$.

A multivariable logistic regression model was built to assess the relationship between $\mathrm{LVH}$ and RDW, controlled for sex and smoking status as categorical variables and age, fasting glucose, serum creatinine, total serum cholesterol, SBP, albumin to creatinine ratio, total cholesterol and HDL-C as continuous independent variables. The results suggested that patients with a higher RDW were more likely to be $\mathrm{LVH}(\mathrm{OR}=1.829,95 \% \mathrm{CI}$ : $1.242-2.694, P=0.002)$.

Other predictive factors for LVH were SBP, serum creatinine, glucose level (Table 3). In hypertensive patients, the receiver operating characteristics (ROC) curves explored the relationship between LVH status and RDW. The area under the curve was 0.688 (95\%CI: 0.635-0.737, $P<0.001$ ) with a cut-off value of 12.9 , the RDW predicted LVH status among hypertensive patients with a sensitivity of $72.4 \%$ and a specificity of $60.3 \%$ (Fig. 2).

\section{Discussion}

This study demonstrates the relationship between RDW and LVH in hypertensive patients. The present data indicates that RDW is significantly increased in hypertensive patients with 
Table 1. Clinical characteristics of hypertensive patients with and without LVH.

\begin{tabular}{|c|c|c|c|}
\hline \multirow[b]{2}{*}{ Parameters } & \multicolumn{2}{|c|}{ left ventricular hypertrophy } & \multirow[b]{2}{*}{$P$} \\
\hline & $\mathrm{No}(\mathrm{n}=174)$ & $\operatorname{Yes}(n=156)$ & \\
\hline \multicolumn{4}{|l|}{ Demographic } \\
\hline Age, y & $46.8 \pm 7.9$ & $46.3 \pm 7.7$ & 0.503 \\
\hline Sex & & & 0.096 \\
\hline Male & $77(58.3 \%)$ & $55(41.7 \%)$ & - \\
\hline Female & $97(49.0 \%)$ & $101(51.0 \%)$ & - \\
\hline Smoking, yes & $22(12.6 \%)$ & $27(17.3 \%)$ & 0.234 \\
\hline Diabetes mellitus, yes & $7(4.0 \%)$ & $12(7.7 \%)$ & 0.153 \\
\hline Body mass index, $\mathrm{kg} / \mathrm{m}^{2}$ & $26.0 \pm 3.5$ & $26.1 \pm 3.6$ & 0.626 \\
\hline \multicolumn{4}{|l|}{ Clinical index } \\
\hline Mean SBP*, mmHg & $133.4 \pm 9.3$ & $138.8 \pm 12.3$ & $<0.001$ \\
\hline Mean $\mathrm{DBP}^{*}, \mathrm{mmHg}$ & $87.0 \pm 7.9$ & $88.8 \pm 10.4$ & 0.083 \\
\hline Triglyceride, mmol/dL L & $1.8 \pm 0.5$ & $1.9 \pm 0.5$ & 0.392 \\
\hline HDL-cholesterol, $\mathrm{mmol} / \mathrm{dL}$ & $1.3 \pm 0.2$ & $1.1 \pm 0.2$ & 0.024 \\
\hline LDL- cholesterol, mmol/dL & $3.2 \pm 0.9$ & $3.1 \pm 0.8$ & 0.129 \\
\hline Total cholesterol, mmol/dL & $5.2 \pm 0.9$ & $5.4 \pm 0.9$ & 0.010 \\
\hline Fasting glucose, mmol/dL & $5.6 \pm 0.6$ & $5.8 \pm 0.6$ & 0.021 \\
\hline Albumin to creatinine ratio, $\mathrm{mg} / \mathrm{g}$ & $32.1 \pm 39.2$ & $47.9 \pm 56.4$ & 0.003 \\
\hline Serum creatine, $\mathrm{mmol} / \mathrm{dL}$ & $67.3 \pm 13.0$ & $71.1 \pm 13.2$ & 0.008 \\
\hline Uric acid, & $341.9 \pm 50.0$ & $347 . \pm 47.4$ & 0.280 \\
\hline Red blood cell, $\times 10^{12} / \mathrm{L}$ & $4.9 \pm 0.4$ & $4.9 \pm 0.4$ & 0.992 \\
\hline Red cell distribution width (\%) & $12.8 \pm 0.6$ & $13.3 \pm 0.8$ & $<0.001$ \\
\hline $\mathrm{Hs}-\mathrm{CRP}^{*}, \mathrm{mg} / \mathrm{dL}$ & $2.3 \pm 5.4$ & $2.6 \pm 4.5$ & 0.678 \\
\hline Hemoglobin,g/L & $148.5 \pm 14.7$ & $149.2 \pm 15.5$ & 0.711 \\
\hline \multicolumn{4}{|l|}{ Echocardiographic examination } \\
\hline $\mathrm{IVST}^{*}, \mathrm{~mm}$ & $9.0 \pm 1.0$ & $10.5 \pm 1.2$ & $<0.001$ \\
\hline LVEDd $^{*}, \mathrm{~mm}$ & $45.4 \pm 4.5$ & $49.5 \pm 4.0$ & $<0.001$ \\
\hline LVESd* $^{*}, \mathrm{~mm}$ & $28.5 \pm 4.0$ & $31.1 \pm 3.5$ & $<0.001$ \\
\hline $\mathrm{PWT}^{*}, \mathrm{~mm}$ & $9.0 \pm 1.9$ & $10.3 \pm 1.3$ & $<0.001$ \\
\hline Ejection fraction, \% & $66.8 \pm 5.3$ & $64.7 \pm 7.1$ & 0.002 \\
\hline Left ventricular mass, $g$ & $169.3 \pm 30.5$ & $236.7 \pm 43.9$ & $<0.001$ \\
\hline Left ventricular mass index, $\mathrm{g} / \mathrm{m} 2$ & $93.5 \pm 12.2$ & $129.7 \pm 19.4$ & $<0.001$ \\
\hline
\end{tabular}

*SBP: systolic blood pressure; DBP: diastolic blood pressure; Hs-CRP: high-sensitive C-reactive protein, IVST: interventricular septal thickness, LVEDd: left ventricular end-diastolic diameter, LVESd: left ventricular end-systolic diameter, PWT: posterior wall thickness

doi:10.1371/journal.pone.0120300.t001

LVH compared with non-LVH group. RDW $>12.9$ measured in patients who have been recently diagnosed as hypertension and who are not receiving any drug treatment had a $72.4 \%$ sensitivity and $60.3 \%$ specificity in predicting LVH. This result suggests cardiac compensation's establishment in the early stages of hypertension and highlights the usefulness of RDW for the early detection of inflammatory status and as a potential marker of target organ damage in hypertensive patients. This study also indicates an association between RDW and LVH and affirms the importance of this index in the full evaluation of hypertensive patients. We noticed that a similar study conducted by Kilicaslan et al had been published in the Hypertension Research [25]. In this study four different geometric patterns (Normal geometry, concentric remodeling, eccentric hypertrophy, concentric hypertrophy) were determined according the 


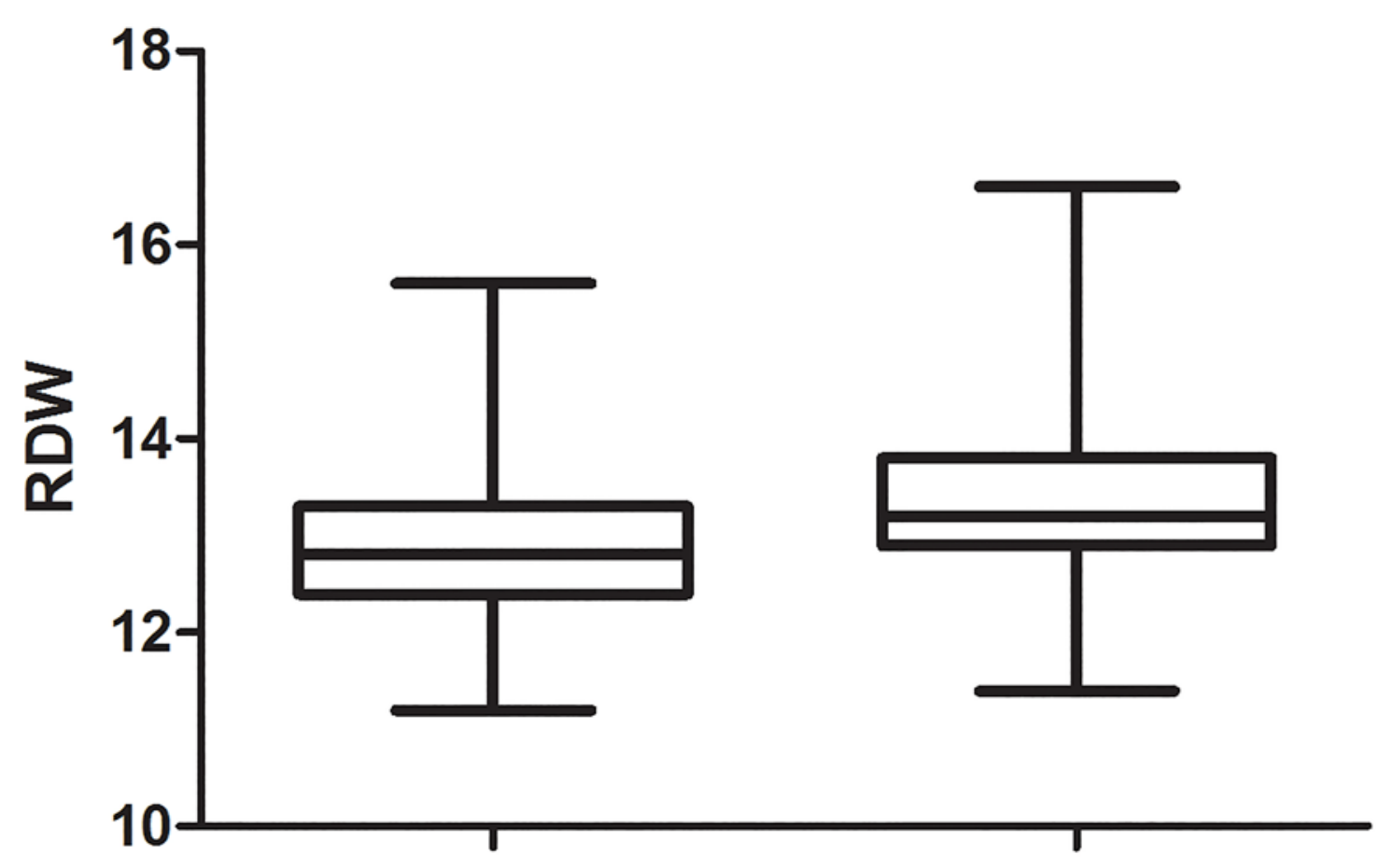

Non-LVH

LVH

Fig 1. Comparison of red cell distribution width (RDW) level between the left ventricular hypertrophy (LVH) group and non-LVH group. doi:10.1371/journal.pone.0120300.g001

LVMI, and they found that LV geometry type were independent associated with high RDW. But the present study encompasses a larger sample size $(n=330)$, which is more than doubled to theirs $(n=139)$. The operating characteristic curve analysis in their study only included concentric hypertrophy $(n=35)$, which makes the results statistically weak. It has been suggested that RDW is an inflammatory marker of $\mathrm{CV}$ diseases, and high-sensitive C-reactive protein, an important inflammatory marker is not assessed in their study. Besides, the result is also questionable in Baris's study, the abstract part showed that LV geometry type is independently

Table 2. Correlation coefficients of relation between red distribution width and some parameters.

\begin{tabular}{llr}
\hline & Correlation coefficients & \multicolumn{1}{l}{ P } \\
\hline Age & -0.023 & 0.083 \\
Mean SBP & 0.471 & $<0.001$ \\
Mean DBP & 0.335 & $<0.001$ \\
left ventricular mass & 0.241 & $<0.001$ \\
left ventricular mass index & 0.264 & $<0.001$ \\
Interventricular septum thickness & 0.095 & 0.085 \\
Left ventricular posterior wall thickness & 0.191 & $<0.001$ \\
Platelet & 0.108 & 0.101 \\
Ejection fraction & -0.132 & 0.016 \\
\hline
\end{tabular}

doi:10.1371/journal.pone.0120300.t002 
Table 3. Multivariable logistic regression analysis of prediction of LVH.

\begin{tabular}{llll}
\hline Variable & Odds ratio & 95\% confidence interval & $\boldsymbol{P}$ \\
\hline Sex(Female) & 0.589 & 0.279 to 1.245 & 0.166 \\
Smoking, yes & 0.672 & 0.306 to 1.478 & 0.323 \\
Ag, y & 0.985 & 0.954 to 1.018 & 0.373 \\
Fasting glucose, $\mathrm{mmol} / \mathrm{dL}$ & 1.594 & 1.059 to 2.401 & 0.025 \\
Total cholesterol, $\mathrm{mmol} / \mathrm{dL}$ & 1.345 & 1.009 to 1.794 & 0.043 \\
HDL- cholesterol, $\mathrm{mmol} / \mathrm{dL}$ & 0.574 & 0.175 to 1.884 & 0.360 \\
Mean SBP, $\mathrm{mmHg}$ & 1.031 & 1.004 to 1.058 & 0.021 \\
Serum creatinine, $\mathrm{mmol} / \mathrm{dL}$ & 1.036 & 1.008 to 1.065 & 0.012 \\
Albumin to creatinine ratio, $\mathrm{mg} / \mathrm{g}$ & 0.996 & 0.990 to 1.003 & 0.280 \\
Red cell distribution width & 2.187 & 1.447 to 3.307 &
\end{tabular}

doi:10.1371/journal.pone.0120300.t003

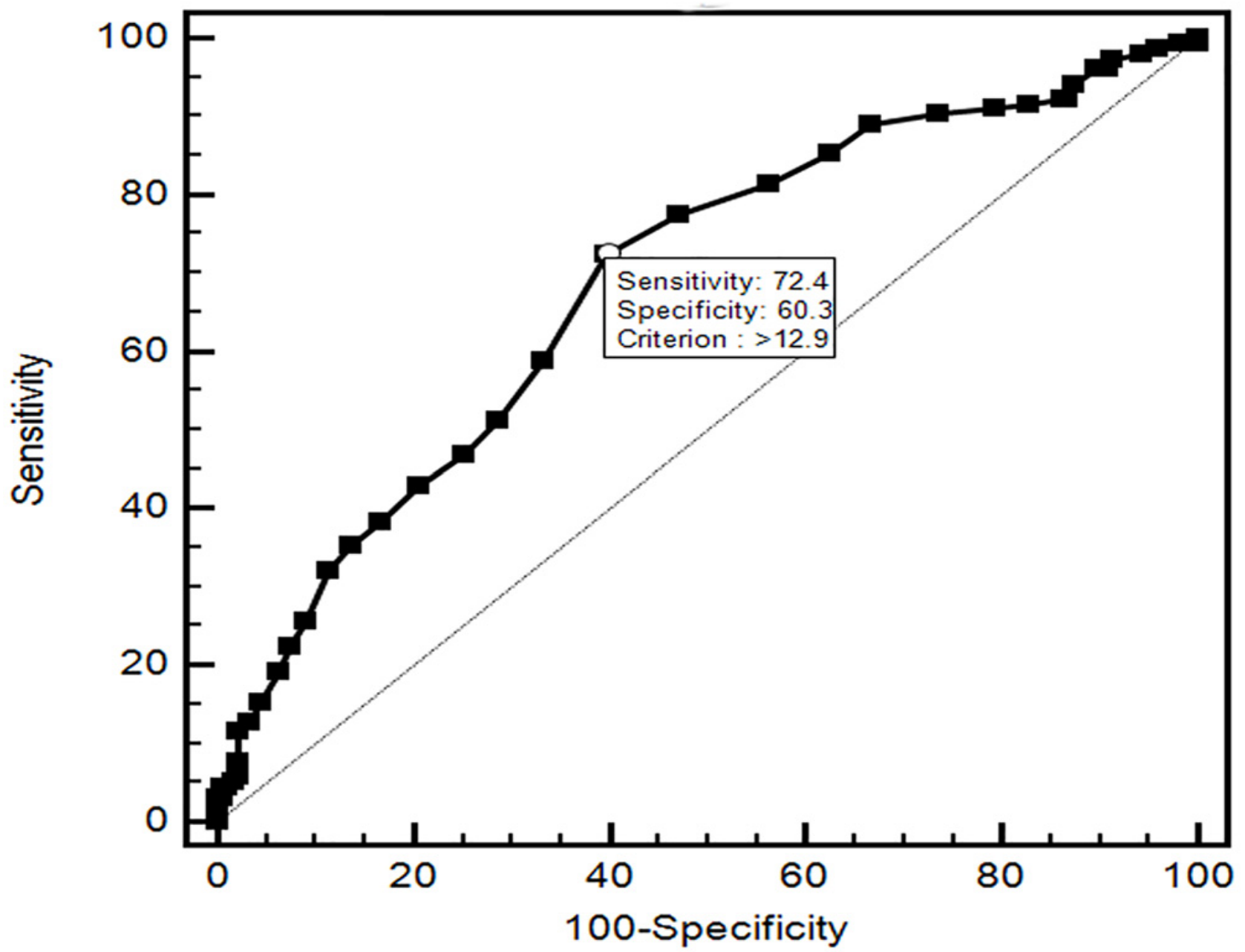

Fig 2. Receiver operating characteristic curve of red cell distribution width (RDW) for predicting left ventricular hypertrophy (LVH) in hypertensive patients.

doi:10.1371/journal.pone.0120300.g002 
predictors of high RDW level, beta $=0.228, P=0.01$. However, the article part give such a wonder result: beta $=0.408, P<0.001$.

The likely explanation of the association between RDW and LVH might be attributed to the presence of chronic inflammation. Chronic inflammation could cause RDW level elevation and increased RDW reflects an underlying chronic inflammation, which could result in a higher risk of cardiovascular disease [26]. Uysal et al. investigated the relationship between RDW and acute ST-elevated myocardial infarction (STEMI) in young patients and found young patients with STEMI had higher RDW level compared with young patients with normal coronaries [27]. Lappe et al. found that RDW was associated with mortality (correlating with hs-CRP levels) in patients with coronary artery disease [28]. But the CRP was not associated with LVH in our study. The reason could be that our results were obtained in a selected population without severe renal function impairment and free of cardiovascular diseases. The association between CRP and LVH would be more significant with the progress of hypertension. This also may highlights that RDW could be a more sensitive indicator in predicting LVH than CRP from the other side. Semba et al. investigated whether serum antioxidants and inflammation predicted RDW values in older women, and the patients in higher quartile of RDW were more likely to have a higher interleukin-6 level [29]. Animal model experiment found that the level of IL-6 in serum was lowered significantly after the Olmesartan Medoxomil completely reversed LVH of rats in renovascular hypertensive prevalence [17]. A previous study suggested IL-6 level was increased in hypertensive patients despite good blood pressure control, and IL-6 could cause cardiac hypertrophy through the IL-6 signal transducing receptor competentglycoprotein 130 [30, 31]. Inflammation may cause changes in red blood cell maturation by disturbing the red cell membrane, leading to increased RDW. Among these echocardiographic indexes, LVM, LVMI, EF, and PWT were correlated with RDW in hypertensive patients. LVM $(\mathrm{r}=0.24, \mathrm{P}<0.001)$, LVMI $(\mathrm{r}=0.26, \mathrm{P}<0.001)$, and IVST $(\mathrm{r}=0.191, \mathrm{P}<0.001)$ had a positive relationship with RDW level while $\mathrm{EF}(\mathrm{r}=-0.13, \mathrm{P}=0.016)$ suggested an inverse relationship with RDW level.

Another important determinant of LVH in hypertensive patients might be oxidative stress that causes oxidative damage. The fact that increased oxidative stress led to activation of signaling pathways and induced cardiac hypertrophy have been found to prevent the development of cardiac hypertrophy [32, 33]. Cave et al. found that Cardiac hypertrophy induced by angiotensin II (Ang II), endothelin-1 (ET-1), tumour necrosis factor (TNF- $\alpha$ ) or pulsatile mechanical stretch, in cultured cardiomyocytes has shown to be involved in intracellular reactive oxygen species (ROS) production, which was inhibited by antioxidants [34]. Takimoto et al. found that uncoupling the nitric oxide synthase-induced ROS production promoted the development of left ventricular hypertrophy during chronic pressure overload [35]. Semba et al. measured RDW at baseline, 12 months and 24 months in 786 moderately to severely disabled women aged more than 65 years old and found serum selenium was a potential predictor of RDW, which suggested that oxidative stress may be a potential underlying biological mechanism for increased RDW [36]. Generally, increased oxidative stress leads to the oxidation and damage of macromolecules, membranes, DNA and enzymes involved in cellular function and homeostasis [37]. Therefore, activation of key mediators of metabolic regulation by ROS as well as depletion or decreased activity of endogenous antioxidants promotes the pathological development of RDW [38].

The present study had several limitations that should be addressed. Frist, because it is limited to a cross-sectional design, establishing causal relationship between RDW and LVH is not sufficient. Second, the study population only included these hypertensive patients without receiving drug treatment. It needs to be further confirmed in the future study. Third, there are some points that RDW alone without other inflammatory markers may not give information 
to clinicians about the endothelial inflammatory condition of patients [39], and RDW should be accessed together with other serum inflammatory markers. But in the multiple regression, controlled for sex and smoking status as categorical variables and age, fasting glucose, serum creatinine, total serum cholesterol, SBP, albumin to creatinine ratio, total cholesterol and HDLC as continuous independent variables, and the analysis still gave a significant result $(\mathrm{OR}=2.187,95 \% \mathrm{CI}: 1.447-3.307, P<0.001)$. Finally, although we demonstrated a significant association between elevated RDW and LVH, we could not determine the exact mechanism of this association.

In conclusion, the present study suggested RDW is a useful tool in predicting LVH in hypertensive patients without treatment. The higher RDW level was observed in the LVH group compared with the non-LVH group. RDW might be associated with LVH in hypertensive patients. These data highlight the role of RDW as a predictor of organ damage in essential hypertensive patients.

\section{Supporting Information}

\section{S1 Dataset. Original data file.}

(XLS)

\section{Acknowledgments}

We thank all our colleagues working in the Department of Epidemiology and Health Statistics, School of public health of Central South University. This work was supported by Graduate Innovation Project of Hunan Province (CX2014B097), and fundamental research funds for the central universities of central south university (2014zzts069), and Hunan Province Science and Technology Project (2014SK2013).

\section{Author Contributions}

Conceived and designed the experiments: ZZL LZC YYL. Performed the experiments: JX CXJ PC. Analyzed the data: ZZL PC. Contributed reagents/materials/analysis tools: JX CXJ. Wrote the paper: ZZL LZC SPY YYH. Revised the manuscript: XQ ZZL LZC.

\section{References}

1. Mancia G, Fagard R, Narkiewicz K, Redán J, Zanchetti A, Böhm M, et al. (2013) Practice guidelines for the management of arterial hypertension of the European Society of Hypertension (ESH) and the European Society of Cardiology (ESC): ESH/ESC Task Force for the Management of Arterial Hypertension. J Hypertens. 2013; 31:1925-38. doi: 10.1097/HJH.0b013e328364ca4c PMID: 24107724

2. Sahn DY, Gur M, Elbansan Z, Kalkan GY, Özdogru I, Kivrak A, et al. (2013) myocardial performance index and aortic dispensability in patients with different left ventricular geometry in newly diagnosed essential hypertension. Blood Press 22: 329-335. doi: 10.3109/08037051.2013.778006 PMID: 23550550

3. Wang SX, Xue H, Zou YB, Sun K, Fu CY, Wang H, et al. (2012) Prevalence and risk factors for left ventricular hypertrophy and left ventricular geometric abnormality in the patients with hypertension among Han Chinese. Chin Med J (Engl) 125: 21-26.

4. Mosterd A, D'Agostino RB, Silbershatz H, Sytkowski PA, Kannel WB, Grobee DE, et al. (1999) Trends in the prevalence of hypertension, antihypertensive therapy, and left ventricular hypertrophy from 1950 to 1989. N Engl J Med 340: 1221-1227. PMID: 10210704

5. Subramaniam A, Shanmugam MK, Perumal E, Li F, Nachiyappan A, Dai X, et al. (2003) Potential role of signal transducer and activator of transcription (STAT)3 signaling pathway in inflammation, survival, proliferation and invasion of hepatocellular carcinoma. Biochim Biophys Acta 1835: 46-60.

6. Zalawadiya SK, Veeranna V, Niraj A, Pradhan J, Afonso L (2010) Red cell distribution width and risk of coronary heart disease events. Am J Cardiol 106: 988-93. doi: 10.1016/j.amjcard.2010.06.006 PMID: 20854962 
7. Sánchez-Chaparro MA, Calvo-Bonacho E, González-Quintela A, Cabrera M, Sáinz JC, FernándezLabandera C, et al. (2010) Ibermutuamur Cardiovascular Risk Assessment Study Group. Higher red blood cell distribution width is associated with the metabolic syndrome: results of the lbermutuamur Cardiovascular Risk assessment study. Diabetes Care 33:e40. doi: 10.2337/dc09-1707 PMID: 20190288

8. Tanindi A, Topal FE, Topal F, Celik B (2012) Red cell distribution width in patients with prehypertension and hypertension. Blood Press 21: 177-181. doi: 10.3109/08037051.2012.645335 PMID: 22243409

9. Vasdev S, Stuckless J, Richardson V (2011) Role of the immune system in hypertension: modulation by dietary antioxidants. Int J Angiol 20: 189-212. doi: 10.1055/s-0031-1288941 PMID: 23204821

10. Zhang Y, Thompson AM, Tong W, XU T, Chen J, Zhao L, et al. (2010) Biomarkers of inflammation and endothelial dysfunction and risk of hypertension among Inner Mongolians in China. J Hypertens 28: 35-40 doi: 10.1097/HJH.0b013e3283324650 PMID: 19770776

11. Ozcan F, Turak O, Durak A, Işleyen A, Uçar F, Ginis Z, et al. (2013) Red cell distribution width and inflammation in patients with non-dipper hypertension. Blood Press 22:80-5. doi: 10.3109/08037051. 2012.707336 PMID: 22835009

12. Fornal M, Wizner B, Cwynar M, Krolczyk J, Kwater A, Korbut RA, et al. (2014) Association of red blood cell distribution width, inflammation markers and morphological as well as rheological erythrocyte parameters with target organ damage in hypertension. Clin Hemorheol Microcirc 56: 325-335. doi: 10. 3233/CH-131745 PMID: 23719424

13. Macdougall IC, Cooper A (2002) The inflammatory response and epoetin sensitivity. Nephrol Dial Transplant 17(Suppl 1): 48-52. PMID: 11812913

14. Levine B, Kalman J, Mayer L, Fillit HM, Packer M (1990) Elevated circulating levels of tumor necrosis factor in severe chronic heart failure. N Engl J Med 323: 236-41. PMID: 2195340

15. Berse B, Brown LF, Van de Water L, Dvorak HF, Senger DR (1992) Vascular permeability factor (vascular endothelial growth factor) gene is expressed differentially in normal tissues, macrophages, and tumors. Mol Biol Cell 3: 211-220. PMID: 1550962

16. Inanc T, Kaya MG, Yarlioglues M, Ardic I, Ozdogru I, et al. (2010) The mean platelet volume in patients with non-dipper hypertension compared to dippers and normotensives. Blood Press 19: 81-85. doi: 10.3109/08037050903516284 PMID: 20367545

17. Li ZC, Yu HY, Wang XX, Zhang M, Wang JP. Olmesartan Medoxomil reverses left ventricle hypertrophy and reduces inflammatory cytokine IL-6 in the renovascular hypertensive rats. Eur Rev Med Pharmacol Sci 2013; 17: 3318-3322. PMID: 24379062

18. Chobanian AV, Bakris GL, Black HR, Cushman WC, Green LA, Izzo JL, et al. (2003) Seventh report of the Joint National Committee on Prevention, Detection, Evaluation, and Treatment of High Blood Pressure. Hypertension 42: 1206-1252. PMID: 14656957

19. Assadi $F$ (2002) Quantitation of microalbuminuria using random urine samples. Pediatr Nephrol 17:107-10. PMID: 11875673

20. Grandi AM, Santillo R, Bertolini A, Imperial D, Broggi R, Colombo S, et al. (2001) Microalbuminuria as a marker of preclinical diastolic dysfunction in never-treated essential hypertensive. Am J Hypertens 14:644-8. PMID: 11465648

21. Sahn DJ, DeMaria A, Kisslo J, Weyman A (1978) Committee on M-Mode Standardization of the American Society of Echocardiography. Recommendations regarding quantitation in M-mode echocardiography: results of a survey of echocardiographic measurements. Circulation 58: 1072-83. PMID: 709763

22. Schiller NB, Shah PM, Crawford M, DeMaria A, Devereux R, Feigenbaum H, et al. (1989) Recommendations for quantitation of the left ventricle by two-dimensional echocardiography. American Society of Echocardiography Committee on Standards, Subcommittee on Quantitation of Two-Dimensional Echocardiograms. J Am Soc Echocardiogr 2: 358-367. PMID: 2698218

23. Devereux RB, Alonso DR, Lutas EM, Gottlieb GJ, Campo E, Sachs I, et al. (1986) Echocardiographic assessment of left ventricular hypertrophy: comparison to necropsy findings. Am J Cardiol 57: 450-8. PMID: 2936235

24. Leoncini G, Viazzi F, Parodi D, Ratto E, Vettoretti S, Vaccaro V, et al. (2004) Creatinine clearance and signs of end-organ damage in primary hypertension. J Hum Hypertens 18: 511-516. PMID: 15002001

25. Kilicaslan B, Dursun H, Aydin M, Ekmekci C, Ozdogan O (2014) The relationship between red-cell distribution width and abnormal left ventricle geometric patterns in patients with untreated essential hypertension. Hypertens Res 37: 560-564. doi: 10.1038/hr.2014.39 PMID: 24599016

26. Felker GM, Allen LA 1, P ocock SJ, S haw LK, Pfeffer MA, et al. (2007) Red cell distribution width as a novel prognostic marker in heart failure: Data from the charm program and the duke databank. J Am Coll Cardiol 50: 40-47. PMID: 17601544

27. Uysal OK, Duran M, Ozkan B, Sahin DY, Tekin K, Elbasan Z, et al. (2012) Red cell distribution width is associated with acute myocardial infarction in young patients. Cardiol J 19: 597-602. PMID: 23224922 
28. Lappe JM, Horne BD, Shah SH, May HT, Muhlestein JB, Lappé DL, et al. (2011) Red cell distribution width, C-reactive protein, the complete blood count, and mortality in patients with coronary disease and a normal comparison population. Clin Chim Acta. 412: 2094-2099. doi: 10.1016/j.cca.2011.07. 018 PMID: 21821014

29. Semba RD, Patel KV, Ferrucci L, Sun K, Roy CN, Guralnik JM, et al. (2010) Serum antioxidants and inflammation predict red cell distribution width in older women: The Women 's Health and Aging Study I. Clin Nutr 29: 600-604. doi: 10.1016/j.clnu.2010.03.001 PMID: 20334961

30. Furumoto T, Saito N, JJ, Mikami T, Fujii S, Kitabatake A (2002) Association of cardiovascular risk factors and endothelial dysfunction in Japanese hypertensive patients: implications for early atherosclerosis. Hypertens Res 25: 475-48. PMID: 12135329

31. Ancy C, Menet E, Corbi P, Fredj S, Garcia M, Rücker-Martin C, et al. (2003) Human cardiomyocyte hypertrophy induced in vitro by gp 130 stimulation. Cardiovasc Res 59: 78-85. PMID: 12829178

32. Luo JD, Zhang WW, Zhang GP, Zhong BH, Ou HJ (2002) Effects of simvastatin on activities of endogenous antioxidant enzymes and angiotensin-converting enzyme in rat myocardium with pressureoverload cardiac hypertrophy. Acta Pharmacol Sin 23: 124-128. PMID: 11866871

33. Sabri A, Hughie HH, Lucchesi PA (2003) Regulation of hypertrophic and apoptotic signaling pathways by reactive oxygen species in cardiac myocytes. Antioxid Redox Signal 5:731-740. PMID: 14588146

34. Cave A, Grieve D, Johar S, Zhang M, Shah AM (2005) NADPH oxidasederived reactive oxygen species in cardiac pathophysiology. Philos Trans R Soc Lond, B, Biol Sci 360: 2327-2334. PMID: 16321803

35. Takimoto E, Champion HC, Li M, Ren S, Rodriguez ER, Tavazzi B, et al. (2005) Oxidant stress from nitric oxide synthase-3 uncoupling stimulates cardiac pathologic remodeling from chronic pressure load. J Clin Invest 115:1221-1231. PMID: 15841206

36. Semba RD, Patel KV, Ferrucci L, Sun K, Roy CN, Guralnik JM, et al. (2010) Serum antioxidants and inflammation predict red cell distribution width in older women: the Women's Health and Aging Study I. Clin Nutr 29: 600-604. doi: 10.1016/j.clnu.2010.03.001 PMID: 20334961

37. Suematsu N, Tsutsui H, Wen J, Kang D, Ikeuchi M, Ide T, et al. (2003) A-Oxidative stress mediates tumor necrosis factor-induced mitochondrial DNA damage and dysfunction in cardiac myocytes. Circulation 107:1418-423. PMID: 12642364

38. Kohler JJ, Cucoranu I, Fields E, Green E, He S, Hoying A, et al. (2009) Transgenic mitochondrial superoxide dismutase and mitochondrially targeted catalase prevent antiretroviral-induced oxidative stress and cardiomyopathy. Lab Invest 89:782-790. doi: 10.1038/labinvest.2009.39 PMID: 19398959

39. Demirkol S, Balta S, Cakar M, Unlu M, Arslan Z, Kucuk U, et al. (2013) Red cell distribution width: a novel inflammatory marker in clinical practice. Cardiol J 20: 209. doi: 10.5603/CJ.2013.0037 PMID: 23558882 